Debate

\title{
Message to complementary and alternative medicine: evidence is a better friend than power Andrew J Vickers*
}

Address: Assistant Attending Research Methodologist, Integrative Medicine, Biostatistics, Memorial Sloan-Kettering Cancer Center, 1275 York Avenue, New York, USA

E-mail: Andrew J Vickers* - vickersa@mskcc.org

${ }^{*}$ Corresponding author

Published: I May 200I

BMC Complementary and Alternative Medicine 200I, I:I
Received: 2 March 2001

Accepted: I May 200 I

This article is available from: http://www.biomedcentral.com/I472-6882/I/I

(c) 200 I Vickers, licensee BioMed Central Ltd.

\begin{abstract}
Background: Evidence-based medicine (EBM) is being embraced by an increasing number of practitioners and advocates of complementary and alternative medicine (CAM). A significant constituency within CAM, however, appears to have substantive doubts about EBM and some are expressly hostile.

Discussion: Many of the arguments raised against EBM within the CAM community are based on a caricature radically at odds with established, accepted and published principles of EBM practice. Contrary to what has sometimes been argued, EBM is not cookbook medicine that ignores individual needs. Neither does EBM mandate that only proven therapies should be used. Before EBM, decisions on health care tended to be based on tradition, power and influence. Such modes usually act to the disadvantage of marginal groups.

Conclusion: By placing CAM on an equal footing with conventional medicine - what matters for both is evidence of effectiveness - EBM provides an opportunity for CAM to find an appropriate and just place in health care.
\end{abstract}

\section{Discussion}

EBM has been sometimes argued to constitute a threat to CAM, interfering with practitioners' daily work, creating problems with funding bodies, perhaps putting even the very survival of CAM in doubt [1]. Such an argument is difficult to square either with current understandings of EBM or with considerations of the alternatives to a strong role for evidence in making decisions about medicine.

\section{An evidence-based approach to EBM}

EBM as often presented by CAM advocates is a caricature unrecognizable from EBM as usually understood. CAM advocates seems to suggest that the only thing that mat- ters in EBM is scientific evidence, that the only scientific evidence that counts is large randomized trials and that the results of these trials should be followed blindly with no place for clinical judgment and assessment of individual patient needs. Accordingly, a typical argument is that EBM constitutes a 'contrasting rhetoric' to the clinical art, intuition and the idiosyncratic nature of the consultation [1]. It is difficult to credit that anyone who has made an attempt to learn about EBM could believe such a claim. For example, the first paper found by the search "What is evidence based medicine?" on the worldwide web is an editorial by Sackett et al [2]. The very first sentence states that EBM is "about integrating individual clinical expertise and the best external evidence." Later 
in the article, Sackett claims that "clinicians who fear top down cookbook [medicine] will find the advocates of evidence based medicine joining them at the barricades". Similarly, the claim that EBM pushes doctors to use only those treatments "research has proven [to] work" [1] bears no relation to anything found in the EBM literature. Quite the opposite, by incorporating decision analysis (see page 138 of Sackett et al's introductory book [3]), EBM provides an explicit framework for incorporation of therapies where evidence is incomplete.

\section{EBM and individualized care}

CAM advocates have sometimes argued that EBM prevents a clinician from varying treatment to meet individual needs. Yet templates for EBM decision-making include issues such as whether the results of a study are applicable to an individual patient and considerations of patient preference. Moreover, there is no reason why individualization cannot be an inherent part of the evidence on which treatment decisions are made. For example, psychotherapy necessarily involves individualization of care. There have been randomized trials of psychotherapy demonstrating a treatment effect [4]. These can be used for evidence-based care of patients experiencing or at risk for psychological distress.

\section{EBM and conventional medicine}

It is hard to think of many figures in conventional medicine that are prepared to go on the record to defend CAM. Advocates of EBM are a notable exception. This is because what matters in EBM is evidence, not how a treatment is currently categorized. For example, Brian Haynes, a long-time advocate of EBM, has criticized in print a paper which, partly on the basis of a "deep model of the physical world", claimed that "the loud signals of alternative medicine [are] false" [5]. Haynes argued that deep models (i.e. theory) are "for snobs, oppressors, and wishful thinkers" and recommended that CAM "embrace empiricism" [6]. Similarly, Iain Chalmers, Director of the UK Cochrane Centre, has called for "a single standard" for evidence of the effects of health care that is applied "across orthodox and complementary medicine" [7]. It is also of note that many EBM textbooks give equal prominence to CAM as to areas such as nursing, surgery and internal medicine [8].

\section{EBM: threat or opportunity for CAM?}

Let us be clear: no one is proposing "1984". There are no EBM thought police snooping around waiting to burst through the clinic door and arrest clinicians caught using treatments not approved by an EBM "big brother". Clinical autonomy is not under threat from EBM. Similarly, no EBM institution is threatening anybody's right to practice: no laws are being proposed to ban those who use therapies not justified by current evidence. With re- spect to funding, it is hard to see the present as a golden age for CAM provision that will come to a close once EBM advocates get into positions of power.

Indeed, the freedoms and opportunities thought by CAM advocates to be under threat by EBM are far more vulnerable to pre-EBM modes of decision-making. Decisions in medicine have often been made on the basis of tradition, power and influence. Such modes of decisionmaking will inevitably work to the disadvantage of marginal groups. It was, after all, the American Medical Association (rather than a research institution) that was found guilty of a "conspiracy" against chiropractic by misuse of its power and influence. The reason why physiotherapy, but not acupuncture, is widely available on the UK National Health Service (NHS) is because the former was in common practice when the NHS was established whereas the latter was not. And what of the argument that medicine's disproportionate reliance of synthetic drugs is due to the financial influence of pharmaceutical companies? If CAM advocates believe that chiropractors should have the right to practice, that acupuncture should have a place in the NHS, and that CAM should replace the use of some pharmaceuticals, then EBM must surely be a welcome change.

\section{Conclusion}

EBM is a shared issue for both conventional medicine and CAM. It is not the case that only conventional medicine is based on evidence or that concerns and misconceptions about EBM are unique to CAM $[9,10]$. By the same token, there are no good reasons to suggest that EBM is somehow incompatible with CAM, or that it works to CAM's disadvantage. Were the CAM community to reject EBM, its future would be decided in the closed-off back rooms of power. I hope instead that CAM advocates chose the open light of evidence and embrace EBM.

\section{References}

I. Adams J: General practitioners, complementary therapies and evidence-based medicine: the defence of clinical autonomy. Complement Ther Med 2000, 8:248-52

2. Sackett DL, Rosenberg WM, Gray JA, Haynes RB, Richardson WS: Evidence based medicine: what it is and what it isn't. $B M$ J 1996, 3 | 2:7|-2

3. Sackett DL, Straus SE, Richardson WS, Rosenberg W, Haynes RB: Evidence-based medicine. London: Churchill Livingstone 2000,

4. Fukui S, Kugaya A, Okamura H, Kamiya M, Koike M, Nakanishi T, Imoto $S$, Kanagawa $K$, Uchitomi $Y$ : A psychosocial group intervention for Japanese women with primary breast carcinoma. Cancer 2000, 89:1026-36

5. Leibovici L: Alternative (complementary) medicine: a cuckoo in the nest of empiricist reed warblers. $B M]$ 1999, 3 19:1629-32

6. Haynes RB: Commentary: a warning to complementary medicine practitioners: get empirical or else. BM] 1999, 319:1632-

7. Chalmers I: Evidence of the effects of health care. Complementary Therapies in Medicine 1998, I I-5

8. Vickers AJ: Complementary Medicine. In CD-ROM accompanying Sackett DL, Straus SE, Richardson WS, Rosenberg W, Haynes RB: Evidence-based medicine. London: Churchill Livingstone 2000, 
9. Grahame Smith D: Evidence based medicine: Socratic dissent. BMJ 1995, 3 10:1 I26-7

10. Tonelli MR: In defense of expert opinion. Acad Med 1999, 74:1187-92

\section{Pre-publication history}

The pre-publication history for this paper can be accessed here:

http://www.biomedcentral.com/content/backmatter/ 1472-6882-1-1-b1.pdf

Publish with BioMedcentral and every scientist can read your work free of charge

"BioMedcentral will be the most significant development for disseminating the results of biomedical research in our lifetime."

Paul Nurse, Director-General, Imperial Cancer Research Fund

Publish with BMc and your research papers will be:

- available free of charge to the entire biomedical community

- peer reviewed and published immediately upon acceptance

- cited in PubMed and archived on PubMed Central

- yours - you keep the copyright

Submit your manuscript here:

http://www.biomedcentral.com/manuscript/

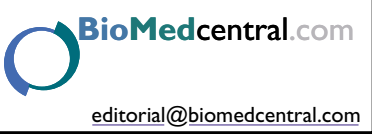

